\title{
The Language Contact Status of Kanbun Kundoku in East Asian Languages
}

\author{
Hongyan Liu \\ School of Foreign Languages \\ Yanshan University \\ Qinhuangdao, China
}

\author{
Qingping Ren \\ School of Foreign Languages \\ Yanshan University \\ Qinhuangdao, China
}

\begin{abstract}
This paper is about the status of Kanbun Kundoku in the language contact among East Asian languages. From the discussion, we concluded that language contact can be in progress in different kinds of medium from the perspective of modern language contact study. Kanbun Kundoku on East Asian can be understood as an example of language contact. From the general type of language contact, Kanbun Kundoku in East Asian history belongs to indirect, long-term and non-cognation language contact based on written form. It belongs to the one-sided impact of longdistance cultural diffusion for thousands of years. Furthermore, the influences are mainly reflected in loanword and part of word order because of the different characteristics of Chinese and target languages.
\end{abstract}

Keywords-Kanbun Kundoku; language contact; ancient Chinese glossing

\section{INTRODUCTION}

Kanbun Kundoku is a common phenomenon of Text Glossing existed in East Asia. It is a type of world Manuscripts Punctuation. This is a way of reading when foreigners make the text glossing in phonetics, semantics and word order by using brush of red and white ink and other tools in cultural circle of ancient Chinese characteristics. The literature with this kind of text glossing has been widely used in all kinds of linguistic studies, named as Kunten Manuscripts. The form of Kunten Mark can be divided into the form of Wokoto Ten and Kaeri Ten in Japan, Chŏ $m$ t'o and Kugyŏl Mark in Korea, Chữ Nôm in Vietnam from the Kunten Manuscripts by now (Whitman 2011). These Kunten Manuscripts are the important materials for the study of foreign written languages and Vernacular Readings and has been widely noticed in historic linguistic study. There is one viewpoint that languages in East Asia have been influenced by Chinese during the process of Kanbun Kundoku (Zisk 2013, Liu 2015). The change in essence can be received as grammatical change caused by a kind of language contact (Heine\&Kuteva 2005).

The essential attributes of Kanbun Kundoku is a prerequisite of language ontology study, which needs to be

This work was supported by MOE (Ministry of Education in China) Project of Humanities and Social Sciences (No.16YJC740044), the Humanities and Social Sciences Projects of Hebei Provincial Department of Education (No.SD161100), and Young Teacher Research Project of Yanshan University (No.15SKB003). in further consideration. From the traditional contact language study, language contact induced language change refering in particular to different languages get influenced and blended with each other in the verbal way. Therefore, before the study of Kanbun Kundoku's influence on East Asian languages by language contact's index and mechanism, we need to answer following questions. The first question is whether Kanbun Kundoku, a written form of language activity, can be received as a kind of language contact. The second question is what kind of status of Kanbun Kundoku. The third question is that which characteristics have compared with other language contacts in traditional meanings. The fourth question is that what kinds of influence can the Kanbun Kundoku on East Asian Languages during process of East Asian languages contacts. The paper will focus on these questions.

\section{THE VIEWPOINT OF ‘EXTENSIVE LANGUAGE CONTACT'}

It is necessary to discuss about language contact connotation before making clear the relationship between language contact and Kanbun Kundoku. Although language contact has been widely used in different fields of linguistic study, there is no unified statement about its intension and extension. Miyashita (2005:50) criticized that language contact has been a general concept since this concept has existed, this concept has been widely used in surrounding phenomenon of different languages' ontology, but there is no unified definition or description. In fact, there are following quoted model of language contact.

According to Weinreich (1974:2), from the perspective of socialinguistics, language contact can be defined as two or more than two languages are used and contacted with each other in a same social group. But Thomason (2001:1) put more emphasis on time and space of language contact. The traditional language concept can be defined as a kind of phenomenon when more than one language is used in the same place. Compared with this, Crystal (2003:102) has a more macroscopic view. The language contact can be described as a status in different languages or dialects when they are close to each other in geography or society. Fishman emphasizes on the result of language contact, we can understand that it is a language that give the direct or indirect influence on another language, which inducing the change from Parole perspective. And this change is speakers' innate 
attribute, which can further influence the development of language history.

Although these concepts vary differently, but they all come from the languages of bilingualism or multilingualism. We cannot judge the Kanbun Kundoku, the common phenomenon in East Asia, is language contact phenomenon just from those concepts. Thomason (2001) made systematic statement about language contact. It was believed that the most important link is to understand the language borderism. To be concise, it is to understand the language contact that happen in the same place, at the same time and in the same group in realistic way. In recent studies of language contact, it is found that films, literature works and internet are the media which can be accepted as the language contact except direct oral contact as the main media. This general language contact view has gradually become the main stream (Thomason 2001:2; Winford 2003:29). From this point of view, language contact media should be diversiform. Language contact will happen as long as there are more than two languages.

\section{The ATtribute OF 'KUndoKU CONTACT'}

Common phenomenon of Kanbun Kundoku in East Asia is a kind of Text Glossing. In order to learn about the Chinese works and Buddhist scripture, the intellectuals in different countries make Vernacular Readings when they read Chinese works. This process can be understood as direct translation. In different types of language alternation, many countries' written language has changed a lot by the influence of Chinese (Liu 2015). Therefore, the Kanbun Kundoku like other language contact can influence language ontology to different degrees from the result. In conclusion, it is inclined to define Kanbun Kundoku as a kind of language contact. The following three things are needed to consider.

First, written form is also a kind of media as language contact. From traditional perspective, the language contact should happen at the same time and at the same place, and it is direct contact without specific media. However, the opposite example is that different languages can have impact on another language even make the target language evolve through the spread of religion books. For example, in the middle ages, written language in western Europe has changed greatly influenced by Latin through the Vernacular Readings about Christian canon. Thai was influenced by Old Pāli when Buddhist scripture was introduced into Thailand. With the influence of Islamism canon, modern Turkish and Malay are affected by the mid-ancient Arabic. From this phenomenon, we know that it is a kind of language contact phenomenon (Thomason 2001:2). Similarly, language contact also happens in East Asian Chinese cultural ring. But language contact media is not sound language, but in the form of vernacular in this situation.

Secondly, translation can also be seen as an important way of language contact. We still have the argument whether Kanbun Kundoku belongs to an argument (Zisk 2013:10). But it is a process when transform the traditional Chinese of source language into other languages in East Asia, so we still receive this as a particular translation form. About the linguistic meaning of translation, it is believed by Baker that it is a kind of social linguistic activity. It is an indirect language contact (2001:164). It is believed that translation can be seen as a kind of language contact, emphasizing that it can bring changes to the target languages. Therefore, the Kanbun Kundoku can be seen as a common translation behavior in East Asian area. It has the general feature of language contact.

\section{The Type of CONTACT IN KANBUn KundoKU}

\section{A. General Type of Language Contact}

From the perspective of time in language contact, it can divide into long-term language contact and short-term language contact. The difference between these two does not depend on the certain length of time, but mainly on continuity of language contact. Long-term language contact is referred to a continuity language contact happened in a long historic period, such as Michif and Chinook Jargon in Pidgin. Short-term language contact is a kind of language contact that only happens in a short period of time using general terms like Shanghai's Chinese Pidgin. Besides, the consideration of standards depends on intensity of contact from language evolution. The long-term language contact is a mild language contact because it is always associated with Superstratum and Stratum, but the short-term language contact is a more intense language contact that it is often connected with war, colonization and trade.

From the perspective of language category system, language contact can also be divided into cognation or noncognation language contact system. The former one has more influence with each other because they belong to the similar language type from phonetics and morphology. The latter one is always reflected in loanword and word order because there is a huge difference between two sides of different languages.

\section{B. The Type of Kanbun Kundoku in Language Contact}

Kanbun Kundoku can be seen as a kind of indirect language contact. To be concise, Kanbun Kundoku happens with the media of written form, not face-to-face language contact like immigration, trade, war and linguistic education, but distant literature disseminate as media. Language contact happens when intellectuals from different countries made vernacular glossing when mid-ancient Chinese literature and Baddish scripts flowed into East Asian countries. Before the recent years, the written language and oral language were different in East Asian countries. It was influenced by the type of Kanbun Kundoku to a certain degree. In other words, Kanbun Kundoku is a kind of language contact, the influence focuses on the level of written language. Kanbun Kundoku has an ultimate goal of culture translation, the same as cultural diffusion. The written language in ancient Chinese gets in contact with other languages in East Asia and influence with each other. Opposite direction of language contact just begins from recent years.

It is different of influence to East-Asian countries of Kanbun Kundoku, but it has a long historic process from previous generation to recent generation. For example, it begins in A.D. 6 century, the process of historic literature 
records have been taken through beginning to the end when Chinese literature flows to Japan. It is commonly believed that the Chinese influence on Japanese was from Heian era. At last, it has become widely used mature Kanbun Kundoku in recent years. From the frequency and intensity of language contact, it can be sure from historical data that influence of Kanbun Kundoku is often reflected in written language of intellectuals in East Asia. The main part of Chinese is about government document and letter. Besides, Chinese character and Chinese article were the general literary attainment which was taught in the group of government officers, so they use the Chinese characters in their literary products. However, for the common people, their own languages are still the main part of language and the extent of influence cannot be verified. From the catalogue of impact, Kanbun Kundoku appeared at low intensity and lasted for thousands of years.

The deep influence of Kanbun Kundoku on East Asian countries cannot be easily realized because the language in Chinese cultural ring is different from Chinese. They belong to different type of language. For example, Chinese has more impact on loanword, word order and word formation in Japanese, Korean and central Asian languages. Kanbun Kundoku brings the new order of these languages by using Kaeri Ten, then by the fundamental of these word order, it has other types of part of speech like conjuction. According to Keesing (1991:316), the language contact which has a huge difference in language type is always named as formulas of equivalence's cognition of formation. This influence is generated by the word to word translation, but the basic feature of target language will not have a complete change by source language.

\section{CONCLUSION}

From the discussion above, language contact can be in progress in different kinds of medium from the perspective of modern language contact study. Kanbun Kundoku, this kind of literature exchange processing formation, also belongs to a kind of language contact. It is similar to universality of Kanbun Kundoku in language contact that it is the vernacular glossing from religious cannon which make language change, so the impact of Kanbun Kundoku on East Asian countries can be understood as one example.

From the general type of language contact, Kanbun Kundoku in East Asian history belongs to indirect, longterm and non-cognation language contact. Therefore, the impact of Kanbun Kundoku on East Asian countries is more focused on written form. It belongs to the one-sided impact of long-distance cultural diffusion for thousands of years with high frequency. Furthermore, the influences are mainly reflected in loanword and part of word order because of the different characteristics of Chinese and target languages.

\section{REFERENCES}

[1] M. Baker and M. Kirsten, Routledge Encyclopedia of Translation Studies. Routledge, 2001.

[2] D. Crystal, The Cambridge Encyclopedia of the English Language. Cambridge University Press, 2003.
[3] J. Fishman, Readings in the Sociology of Language. Mouton, 1968.

[4] B. Heine and T. Kuteva, Language Contact and Grammatical Change. Cambridge University Press, 2005.

[5] R. Keesing, "Substrates, Calquing and Grammaticalization in Melanesian Pidgin," Approaches to Grammaticalization. John Benjamins, 1991, pp. 315-342.

[6] H. Liu, "An Empirical Study of Contact-induced Grammatical Changes and Grammatical Relications," Dissertation of Kyushu University, 2015.

[7] N. Miyashita, Gengosesshoku to Tyugoku-Tyosengo no Seiritsu. Kyushu Daigaku Syuppankai, 2007.

[8] P. Siemund and N. Kintana, Language Contact and Contact Languages. John Benjamins Publishing, 2008.

[9] S. Thomason, Language Contact. Edinburgh University Press, 2001.

[10] U. Weinreich, Languages in Contact: Findings and Problems.Mouton, 1974.

[11] J. Whitman, "The Ubiquity of the Gloss," Scripta vol.2, 2011, pp.95121.

[12] D. Winford, An Introduction to Contact Linguistics. Blackwell Publishing, 2003.

[13] M. Zisk, "Research on Semantic Borrowing via Chinese Characters in Japanese," Dissertation of Tohoku University Graduate School of Arts and Letters. 2013. 